\title{
Integrity Assessment of Pipe System in a Full-Scale Membrane Water Treatment Plant
}

\author{
H. K. Oh1, J. Y. Eom¹, S. H. Kang1, H. C. Yoo', Y. J. Kim², D. M. Yoon'2, J. H. Lim³ \\ ${ }^{1}$ Daewoo Institute of Construction Technology, Suwon City, Korea \\ ${ }^{2}$ The Office of Waterworks Seoul Metropolitan Government, Seoul, Korea \\ ${ }^{3}$ Next Engineering \& Service, Seoul, Korea \\ Email: heekyong.oh@daewooenc.com
}

Received 20 January 2014; revised 18 February 2014; accepted 15 March 2014

Copyright (C) 2014 by authors and Scientific Research Publishing Inc.

This work is licensed under the Creative Commons Attribution International License (CC BY). http://creativecommons.org/licenses/by/4.0/

(c) (i) Open Access

\begin{abstract}
The pipe system roles as a main bridge between membrane modules and pumps in membrane water treatment plants. Membrane operation modes generally consist of filtration and backwash processes in a normal mode, a pressure decay test as an integrity test and a chemical circulation through pipe system in a cleaning mode. Thus factors effecting on membrane performance should be sufficiently considered before design and operation. This study evaluated flow analysis for vibration diagnostic and evaluation of the fatigue lifetime in the microfiltration system applied for a drinking water treatment plant. Vibration of main membrane pipelines was measured to identify the source of vibration. Also natural frequency and fluid dynamics was calculated by computational fluid dynamics. It showed that maximum magnitude frequencies were at $12 \mathrm{~Hz}$ and $22 \mathrm{~Hz}$, respectively at water and air pipeline during filtration and backwash. Backwash process caused mainly vibration on the backwash water pipe. The calculated frequency from analysis of frequency response and CFD was in a good agreement with the measured frequency. Fatigue analysis showed that pipelines were getting little damage caused by vibration. Fatigue lifetime was predicted more than 15 years under the operation condition of daily filtration, and more than 27 years under the operation condition of a daily backwash mode, resulting in minor damage on the pipe lifetime.
\end{abstract}

\section{Keywords}

Fatigue; Integrity; Lifetime; Membrane; Pipe System; Vibration

\section{Introduction}

A number of pilot and full-scale investigations confirmed the advantages of membrane system as microbial barrier in drinking water treatment allowing a small footprint and easy operation and quick installation [1]-[4]. 
However, some failures and malfunction when membrane plants are designing and operating can have an effect on the membrane performance in the terms of safe and sable water production [5]. Design failures are come from inadequate module array, uneven fluid distribution in membrane skid pipes, insufficient pretreatment for membrane process, improper instrument selection and etc. Operation malfunctions are usually reported by membrane fouling, membrane damage, insufficient recovery and unreasonable increase of transmembrane pressure [6] [7]. Those failures may occur progressively and suddenly through the membrane operation. Thus some factors effecting on the performance in the membrane water treatment plant such as in plant engineering should be sufficiently considered during design and operation. As the life time of membrane water treatment plants like other plant facilities reaches their design life, the accident potential events may increase due to the aging effects [8].

Integrity of components in the plant system has been investigated through real-time monitoring by direct and indirect method, life-time expectation and diagnosis [9]. In the case of the membrane water treatment plant for drinking water, failures of membrane fibers or sheets have been mainly considered as main items for integrity monitoring, because pathogens may pass through the broken membrane fibers and sheets [10]. The integrity tests specific for the membrane type depend on the membrane manufacturer and membrane system supplier. Indirect methods monitor the permeate particle behavior using on-line particle counter and turbidity meter, but not so sensitive to the membrane failures. Generally, direct methods as membrane integrity monitoring techniques were adopted by pressure decay test (PDT), diffusive air flow (DAF) test, and bubble point test [11]-[16]. In addition, numerous researches have been performed to establish the detection method of broken fibers and instrument faults in a membrane array; acoustic sensor test, integrity sensor, surrogate usages [17]-[19]. Failures of membrane fibers resulted from chemical corrosion, faulty installation and maintenance, stress and strain from operating conditions and fiber damage by some coarse debris not removed by pretreatment. Especially fouling status of a membrane, the number of applied back pulses and chemical contact for cleaning are significant aging factors for the membrane fibers.

Introduction of integrity assessment of piping components is also essential for safe and reliable operation in membrane plants. Flow induced vibration, valve on/off work and usage of chemicals and air can cause regular or irregular stress or fatigue on the pipe network and related apparatus such as valve, pump, metering instrument and membrane module. Korea's experience of the membrane operation at home has approximately 10 years with $1 \%$ application rate of membrane plant for drinking water (based on capacity). The mechanical evaluation of pipe failures has evolved over time. The main effort in evaluating the mechanical and structural behavior or pressurized components started at the other plant engineering such as power and process plant since 1950 [20]-[24]. The integrity engineering is associated with the design, assurance, and verification functions that ensure a product, process or system meet its appropriate and intended requirements. Thus application of integrity engineering into the membrane system from membrane fibers to program, can minimize cost, risks in schedule, technical and legal, improve the overall life cycle cost and provide safe water quality and high system reliability for the intended period of operation (Figure 1). Therefore, mechanical integrity and safety researches are required in order to produce safe water in both terms of quality and quantity in membrane systems.

The pipe system roles as a main bridge between membrane modules and pumps in a membrane water treatment plants. Membrane operation modes generally consist of filtration and backwash in a normal mode, a pressure decay test in an integrity test and chemical circulation in a cleaning mode. Thus some factors effecting on the membrane performance should be sufficiently optimized before design and operation. In this study, the source and cause of vibration in pipe system were identified through vibration measurement and flow analysis using CFD (Computational Fluid Dynamics), LES (Large Eddy Simulation) and FFT (Finite Fourier Transform). In addition, natural frequency of pipe and fluid were analyzed and fatigue lifetime was predicted for pipe system during membrane operation.

\section{Materials and Methods}

\subsection{Membrane System Operations}

Microfiltration (MF) membrane plant was designed as a hybrid system for treating river water; rapid mixingcoagulation-sedimentation-microfiltration-ozone oxidation-granular activated carbon-disinfection. The raw water had seasonal events such as low temperature in winter season, high turbidity in rainy season (Figure 2). Total organic carbon (TOC) data as an organic membrane foulant were moderate for the hybrid membrane system. TOC data lost through analyzer failure between December 2012 and February 2013. Coagulation and sedimentation 


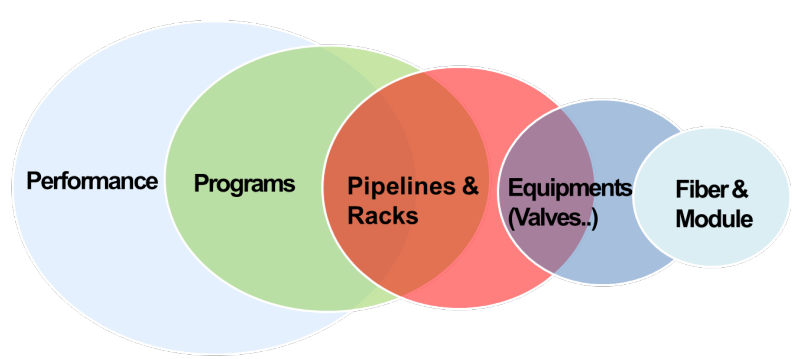

Figure 1. Integrity assessment for a membrane treatment system.

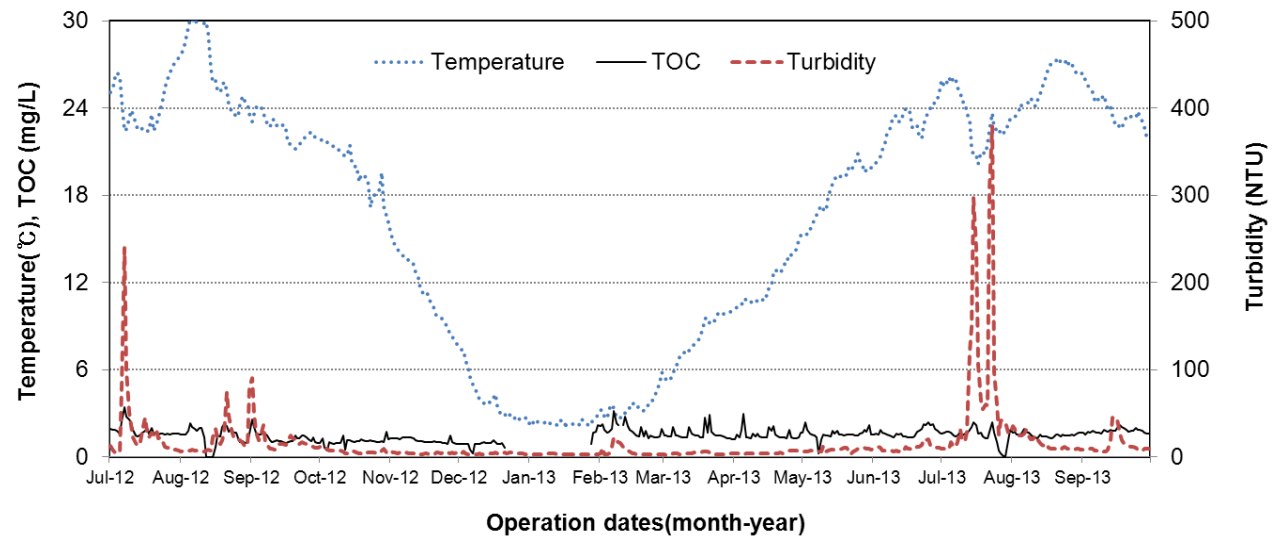

Figure 2. Characteristics of raw water used for MF membrane plant.

processes reduce fouling load from organic matters and particulates. They provide a buffer zone with a hydraulic retention time before the MF membrane process.

Membrane operation conditions are summarized in Table 1. Design capacity was 25,000 $\mathrm{m}^{3} /$ day using 252 membrane modules. Membranes were arranged in 6 racks (or skids) and 42 membrane modules were installed in one rack. In the filtration and backwash modes, water and air were circulated the pipe system linked with pump and membrane module. In the cleaning mode, acidic and alkaline chemicals were circulated between chemicaltank and membrane modules through the pipe system. In addition, only the air was applied to the membranemodules for 7 minutes during the pressure decay test (PDT). Thus various fluid types and air were moving in the pipe system and they caused flow induced vibration, noise, corrosion.

\subsection{Vibration Measurement}

Vibration was measured by vibration analyzer (Emerson, CSI 2130) available for getting the normal periodic vibration spectrum and wave form from element of the membrane pipe system. The monitoring points were decided based on the vibration potential source; membrane modules, feed pipe, circulation pipe, discharge pipe, air pipe, pumps and valve lack (Figure 3). Frequency of vibration per individual operation modes of filtration and backwash were measured 20 times for precision and reproducibility.

\subsection{Fluid Analysis Model}

Computational fluid dynamics (CFD) is used for predicting fluid flow in the membrane pipe system by solving numerically the set of governing mathematical equations. Fluid flow in the pipe system is analyzed by non-linear partial differential conservation equations of mass and momentum which are obtained by control volume as follows.

The continuity equation:

$$
\nabla \cdot\left(\rho_{m} v\right)=0
$$

where, $v$ : velocity vector, 
Table 1. Operation conditions of microfiltration treatment system.

\begin{tabular}{ccc}
\hline Items & Conditions & Notes \\
\hline Design flux (LMH, l/m².hr) & $42-83$ & Average design flux: 55 LMH \\
Recovery, R (\%) & 96 & $\mathrm{R}=$ (product-backwash)/feed $\times 100$ \\
Cycle (times/year) & & Cycle: feed-filtration-backwash-drain \\
- Filtration (water) & 12,000 & 40 min \\
- Backwash (water + air) & 12,000 & $1 \mathrm{~min}$ \\
- Drain (wastewater) & 12,000 & 0.5 min \\
- Maintenance cleaning (chemical) & 31 & Weekly (rainy season), monthly \\
- Chemical cleaning (chemical) & 2 & Every 6 months \\
- PDT as integrity test as (air) & 365 & Daily \\
\hline
\end{tabular}

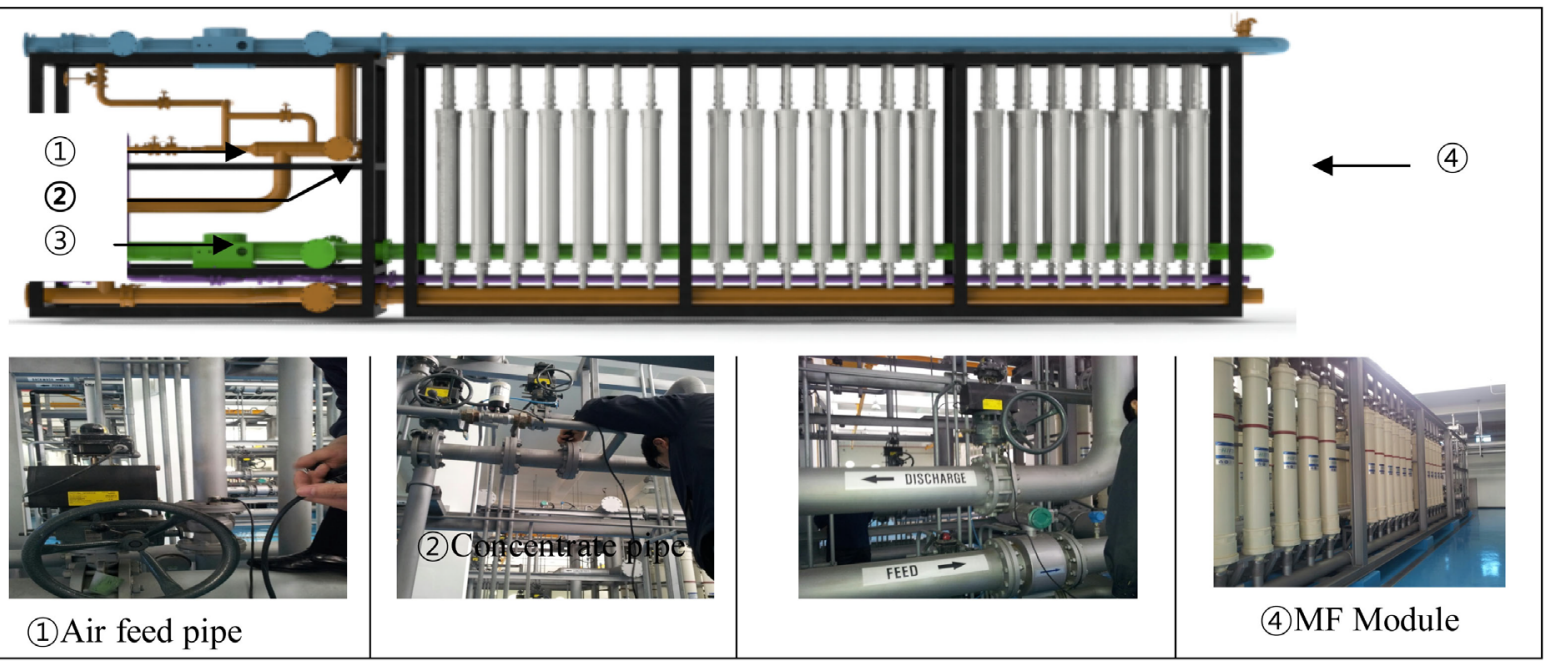

Figure 3. Vibration measurement of the MF membrane system.

$\rho_{m}$ : density of mixture fluid (is computed using "volume weighted mixing law" such as $\rho_{m}=\frac{1}{\sum_{i} \frac{Y_{i}}{\rho_{i}}}$ )

$Y_{i}$ : mass fraction of the individual species

The momentum equation: (Navier-Stokes Equation)

$$
\nabla \cdot\left(\rho_{m} \boldsymbol{w}\right)=-\nabla p+\nabla \cdot \tau_{m, \text { eff }}+\rho_{m} \boldsymbol{g}
$$

where, $p$ : system pressure

$\tau_{m, e f f}:$ effective stress tensor $\left(=\mu_{m, e f f}\left[\left(\nabla \boldsymbol{v}+\nabla \boldsymbol{v}^{\mathrm{T}}\right)-\frac{2}{3} \nabla \cdot \boldsymbol{v} I\right]\right)$

$\mu_{m, \text { eff }}$ : effective viscosity of mixture fluid $\left(=\mu_{m}+\mu_{m, t}\right)$

$\mu_{m}$ : viscosity of mixture fluid

$\mu_{m, t}$ : turbulent viscosity of mixture fluid $\left(=\rho_{m} C_{\mu} \frac{k^{2}}{\varepsilon}\right)$

$\boldsymbol{g}$ : gravity vector

Energy balance equation:

$$
\frac{\partial\left(\rho_{m} E\right)}{\partial t}+\nabla \cdot\left(\rho_{m} E \boldsymbol{v}\right)=\nabla \cdot\left(\kappa_{m, e f f} \nabla T\right)+\nabla \cdot\left(\tau_{m, e f f} \cdot \boldsymbol{v}\right)-\nabla \cdot(p \boldsymbol{v})+S_{h}
$$


$\kappa_{m, \text { eff }}$ : effective thermal conductivity of mixture fluid $\left(=\kappa_{m}+\kappa_{m, t}\right)$

Turbulence model (realizable $k-\varepsilon$ model)

$$
\begin{gathered}
\nabla \cdot\left(\rho_{m} k \boldsymbol{v}\right)=\nabla \cdot\left[\left(\mu_{m}+\frac{\mu_{m, t}}{\sigma_{k}}\right) \nabla k\right]+G_{k}+G_{b}-\rho_{m} \varepsilon-Y_{M} \\
\nabla \cdot\left(\rho_{m} \varepsilon \boldsymbol{v}\right)=\nabla \cdot\left[\left(\mu_{m}+\frac{\mu_{m, t}}{\sigma_{\varepsilon}}\right) \nabla \varepsilon\right]+\rho_{m} C_{1} S \varepsilon-\rho_{m} C_{2} \frac{\varepsilon^{2}}{k+\sqrt{v \varepsilon}}+C_{1 \varepsilon} \frac{\varepsilon}{k} C_{3 \varepsilon} G_{b}
\end{gathered}
$$

Large eddy simulation (LES) is used to calculate pressure change by the flow turbulence.

As previously stated, analysis domain is separated from each control volume applied before equations. Each control volume called grid or cell and usually grid (cell) configuration is tetrahedron or hexahedron in three dimensional. Each grid (cell) store all physical quantity in the center and each cell are applied the conservation law. This is the Finite Volume Method (FVM). Figure 4 shows the discretization process using FVM about the control volume.

As shown above, center of each control volumes are $\mathrm{W}, \mathrm{P}, \mathrm{E}$ and adjacent sides are $w, e$. The below equation indicates conservation formula of scalar $\Phi$ in 1-dimension steady state and mass, momentum conservation equation is same form

$$
\frac{\partial(\rho u \Phi)}{\partial x}=\frac{\partial}{\partial x}\left(\Gamma \frac{\partial \Phi}{\partial x}\right)+S_{\Phi}
$$

Control volume $\mathrm{P}$ is integrated using this formula and applied divergence theorem. Left convection term is,

$$
\int_{\text {Volume } V} \frac{\partial(\rho u \Phi)}{\partial x} \mathrm{~d} V=\int_{\text {surface } A} \rho u \Phi \mathrm{d} A=(\rho u \Phi A)_{e}-(\rho u \Phi A)_{w}
$$

Right diffusion term and source term is,

$$
\int_{\text {Volume } V}\left[\frac{\partial}{\partial x}\left(\Gamma \frac{\partial \Phi}{\partial x}\right)+S_{\Phi}\right] \mathrm{d} V=\left(\Gamma \frac{\partial \Phi}{\partial x} A\right)_{e}-\left(\Gamma \frac{\partial \Phi}{\partial x} A\right)_{w}+S_{\Phi} \Delta V
$$

Because all variables are stored $\mathrm{P}, \mathrm{W}$ and $\mathrm{E}$ which are center of control volume, values of $\Phi, e$ and $w$ should be calculated form cell center. There are several computation methods to solve these values; first order upwind scheme, power-low scheme, second order upwind scheme.

In this way, integral formula is generated and each control volumes are applied this formula and then integrated. Namely, it is changed from Partial Differential Equations (PDE) which cannot be calculated by computer or matrix solver to algebraic equation which can be calculated by computer or matrix solver.

$$
a_{p} \Phi_{p}=\sum_{n b} a_{n b} \Phi_{n b}+b
$$

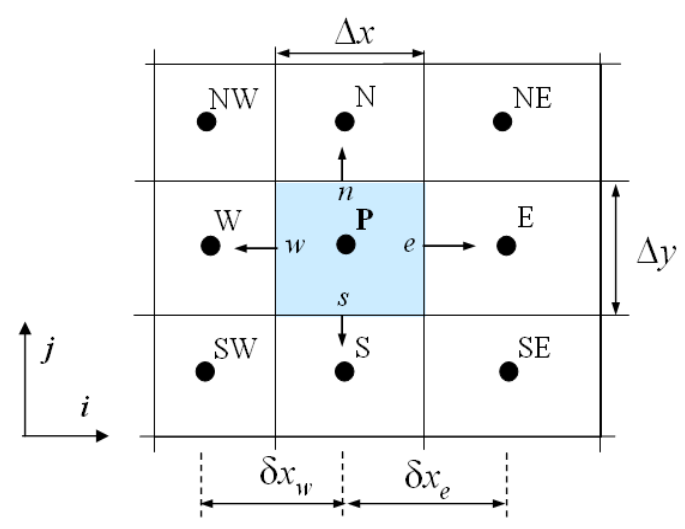

Figure 4. Control volume for 2D. 
Here, $n b$ is neighbor control volume of control volume P. 2-D quadrilateral grid has 4 neighbor cells and 3-D Hexahedron grid has 6 neighbor cells.

$a_{p}$ and $a_{n b}$ is $\Phi$, this is a nonlinear equation and calculated by iteration.

Vibration was measured by vibration analyzer (Emerson, CSI 2130) available for getting the normal periodic vibration spectrum and waveform from element of the membrane pipe system. The monitoring points were decided based on the vibration potential source; membrane modules, feed pipe, circulation pipe, discharge pipe, air pipe, pumps and valve lack. Frequency of vibration per individual operation modes of filtration and backwash were measured 20 times for precision and reproducibility

\subsection{Frequency Response Model}

Frequency response analysis is used to check that the frequency response characteristic of the structure. This allows the natural frequency $\left(\omega_{i}\right)$ and the mode shape of frequency response $\left(\Phi_{i}\right)$ can be confirmed.

The governing mathematical equations are expressed as follows.

$$
\left([K]-\omega_{i} \omega_{i}[M]\right) X \Phi_{i}=0
$$

where $[M]$ is mass matrix and determined by the material properties, the shape and thickness of the structure. $[K]$ is stiffness matrix and determined by material properties. $\omega_{i}$ is natural frequency ofvibration analysis and $\Phi_{i}$ is the mode shape.

Assumption for the frequency response model is as follows:

- $\quad[K]$ and $[M]$ are uses as a constant $K$ and $M$;

- Linear static analysis;

- Not included the damping effect and loading conditions;

- No external force;

- Matrix $[\Phi]$ is relative value.

If the material of the structure is determined, material properties of density, elastic modulus and poisson's ratio can be applied to compute the above equation. If we know the natural frequency of structure and the natural frequency of vibrations with each other, the damage of the structures due to the resonance can be prevented.

The model size for response analysis is $4200 \times 1960 \times 3500(\mathrm{~mm})$ and grid size is $10 \times 10(\mathrm{~mm})$. The total grid numbers are 168,018 and size of pipe model is 10S. The analysis conditions of pipe material and specification are suggested in Figure 5. Constraints of the analytical model were confirmed through field verification and 2D CAD drawing. In particular, the end of the pipe and the connection part were boundary conditions to reflect the conditions. More detail constraints shown below Figure 5.

\subsection{Fatigue Analysis Model}

Fatigue is the weakening or destruction of a material caused by repeatedly applied loads over a period of time. To analyze fatigue, it is necessary to define the applied load. In this study, the vibration was applied to the measured data of load conditions. Fatigue has three input conditions that are geometry, loading data and materials data.

S-N curve used for fatigue analysis is a characteristic of the material. In high-cycle fatigue situations, materials performance is commonly characterized by an S-N curve. This is a graph of the magnitude of a cyclic stress (S) against the logarithmic scale of cycles to failure $(\mathrm{N})$. For fatigue analysis, static analysis on the structure was performed to obtain the stress samplitude. Then the results were applied to the S-N curve, and the fatigue life can be identified. Fatigue analysis condition and load position are shown in Figure 6 .

\section{Results and Discussions}

\subsection{Maximum Magnitude Frequency of Each Pipe System}

Vibration measurement showed that maximum magnitude frequencies (MMF) were at $12 \mathrm{~Hz}$ and $22 \mathrm{~Hz}$, respectively at water and air line during the filtration mode (Figure 7). The MMF occurred at $13 \mathrm{~Hz}$ of discharge line, $18 \mathrm{~Hz}$ of concentrate line and $18.5 \mathrm{~Hz}$ of air line during the backwash mode however magnitudes of the maximum frequency measured during the filtration and backwash modes were minor (Figure 8). 


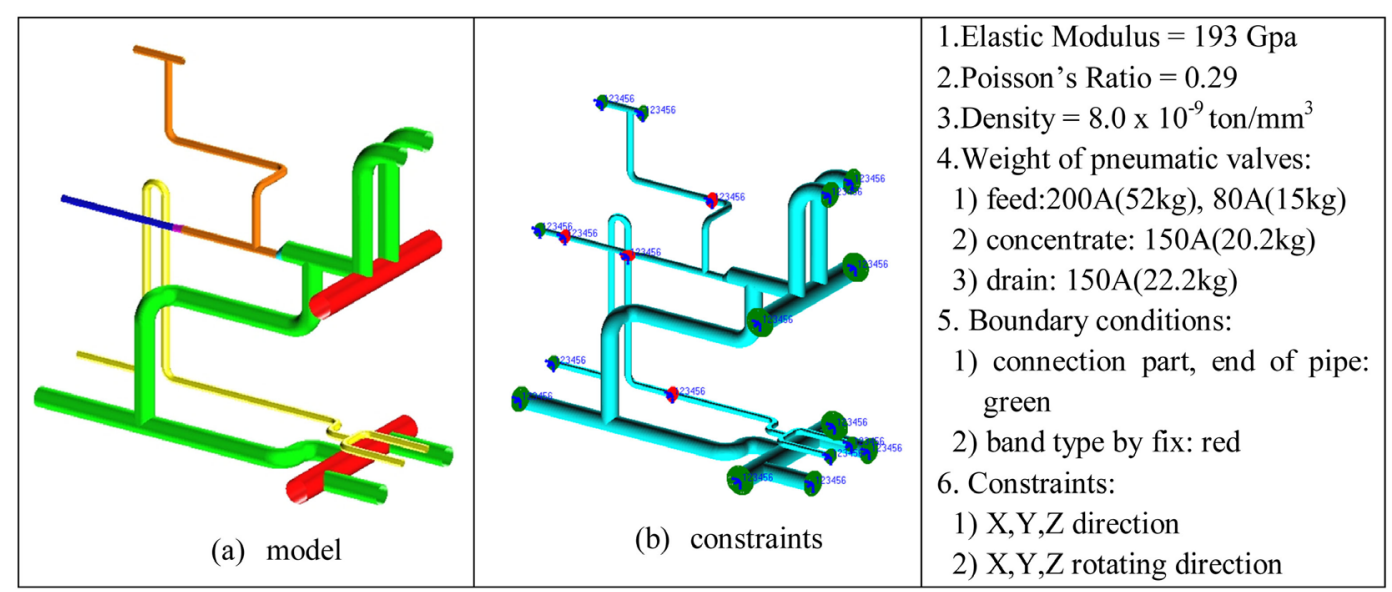

Figure 5. Model and constraints for response analysis..

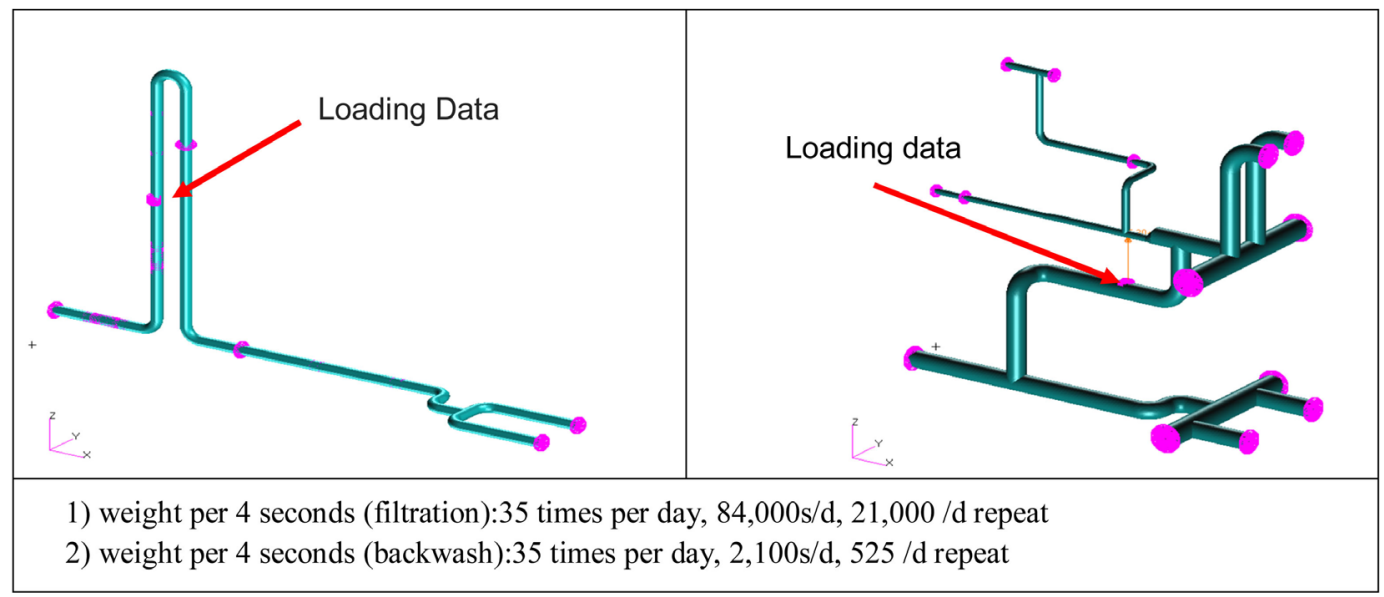

Figure 6. Analysis conditions and load positions for fatigue analysis.

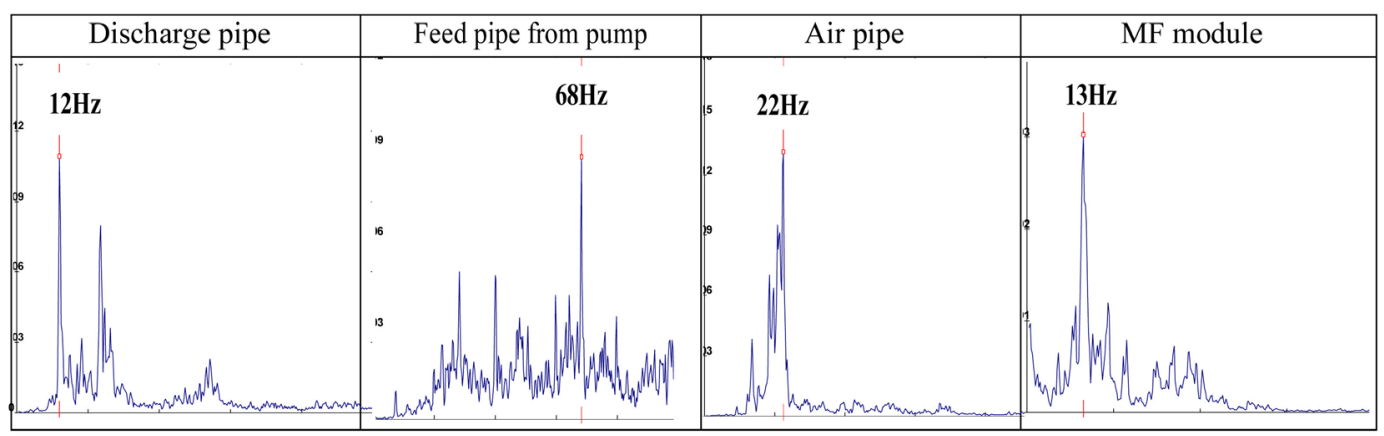

Figure 7. PK acceleration (y-axis) and frequency (x-axis) of system element at filtration mode.

\subsection{Frequency Response of Fluid and Air during Operation Modes}

The frequency response analysis was expressed from 1st mode to 8th mode using information of the pipes and valves. The shapes in each mode appeared mixing of vibration, twist and bending and 1st mode was easy to show the frequency of each fluid pipe. In the case of the water and air passing through the pipe during the backwash mode, the frequency responses were obtained by $13.33 \mathrm{~Hz}$ and $22.69 \mathrm{~Hz}$, respectively (Figure 9). The analyzed frequency of discharge pipe $(13.3 \mathrm{~Hz})$ was in a good agreement with the measured frequency $(12-13 \mathrm{~Hz})$. However, the frequency response analysis of air line $(22.69 \mathrm{~Hz})$ was not matched the measured data $(18 \mathrm{~Hz})$. It 


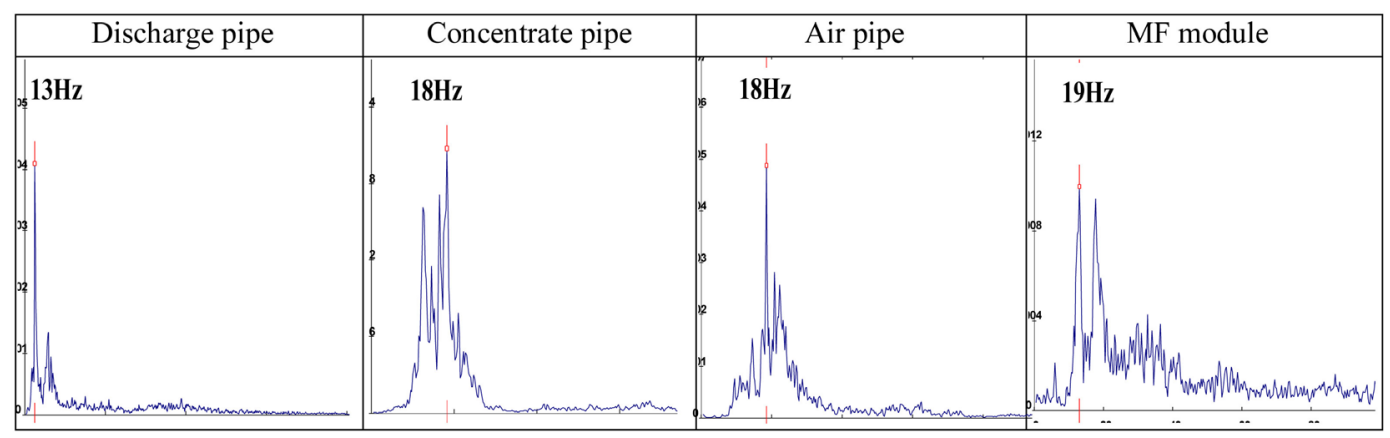

Figure 8. PK acceleration (y-axis) and frequency (x-axis) of system element at backwash mode.

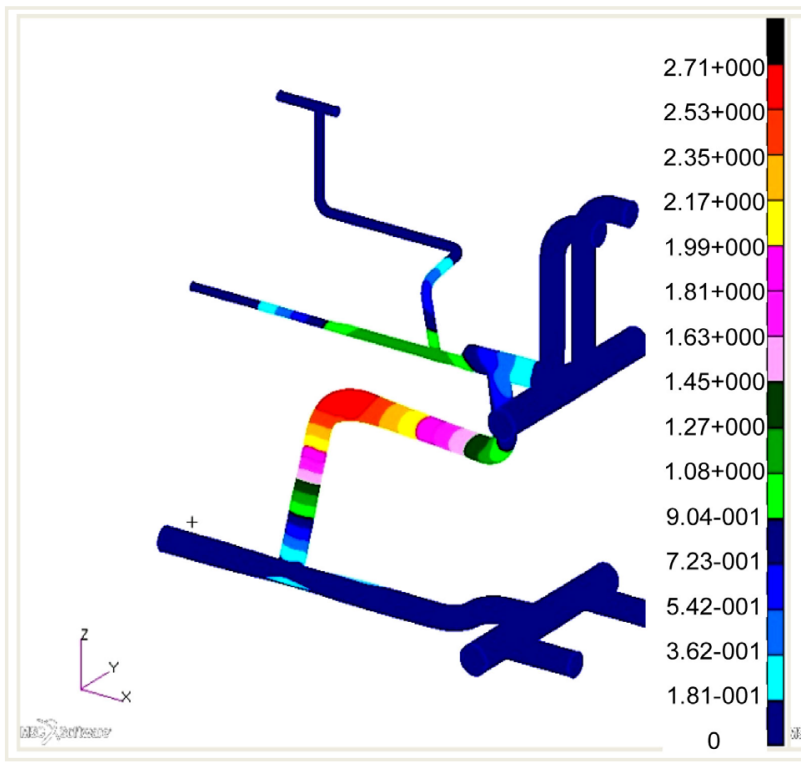

(a)

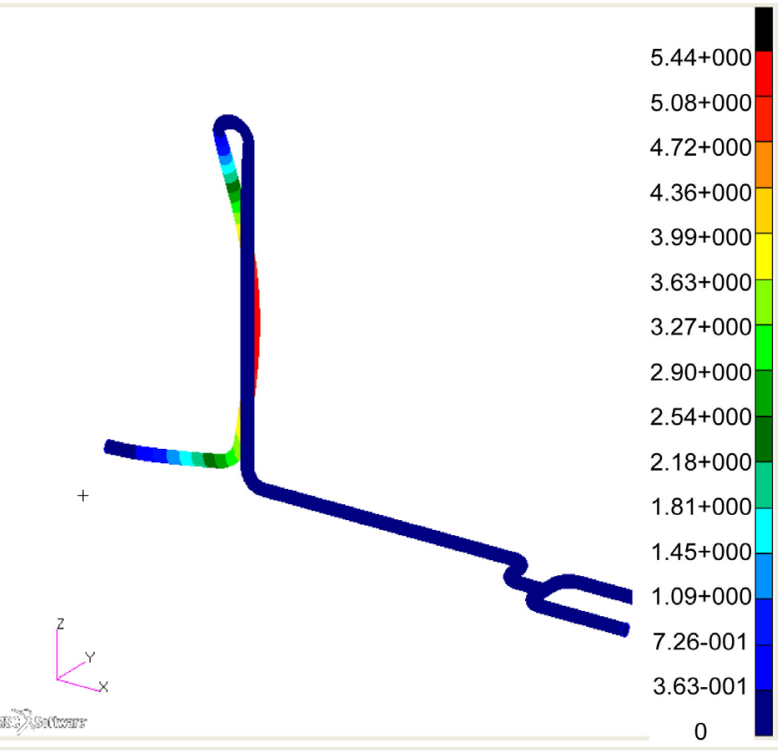

(b)

Figure 9. Frequency response analysis of fluid and air pipes during the backwash. (a) 1st mode of water pipe, 13.33 Hz; (b) 1st mode of air pipe, $22.69 \mathrm{~Hz}$.

was confirmed that air was identified with no main vibration factor during the backwash but vibration in the discharge line was caused by backwash flow. Some errors between the measured and analyzed data came from the errors of real information such as valve weight and geometry of pipe system. The water passing the pipe was determined by the cause of oscillation. Based on this result, it was necessary to determine the durability of fluid pipe by fatigue analysis.

\subsection{Fluid Analysis}

CFD analysis was performed separately for water and air pipes. Mesh for CFD was used Hex. Mesh to get a good quality in the fluid analysis. The bending pipe was subject to extreme changes in the flow motion. Thus the bending pipe created precisely the detailed grid, resulting in accurate prediction. Boundary conditions were used by the backwash operation condition; $290 \mathrm{~m}^{3} / \mathrm{h}$ of water volume in pipe, $310 \mathrm{~m}^{3} / \mathrm{h}$ of air volume in pipe. The results could identify pressure changes in the fluid pipe segments (Figure 10). The fluid pressure was used to identify the oscillation frequency.

In the case of the air passing through the pipe, $6 \mathrm{~Hz}$ frequency was generated by the air flow. But the results was significant difference from the frequency response analysis $(22.7 \mathrm{~Hz})$ and measured data $(18.5 \mathrm{~Hz})$. Air flow was confirmed to be no factor to cause vibration in the membrane system. In the case of the water passing through the pipe, 11 - $13 \mathrm{~Hz}$ frequency was generated by the flow. The result was almost similar to the frequen- 
cy response analysis $(13.3 \mathrm{~Hz})$ and measured vibration data $(12.7 \mathrm{~Hz})$. Therefore, the back washing flow of the waterline was the cause of vibration in the membrane system (Figure 11).

\subsection{Fatigue Analysis}

Fatigue analysis was divided by filtration and back wash modes. The fatigue analysis under the filtration mode showed that the pipeline were getting little damage caused by vibration, so fatigue lifetime was predicted more than 15 years (Figure 12). If the vibration load from the backwash mode produced to the pipeline for $24 \mathrm{hr}$, it was predicted more than 27 years and resulted in minor damage on the pipe (Figure 13). In the case of the air passing through the pipe, damage result was much less than the water pipe analysis results. But the back washing process generated only 35 times atone day. Considering the real backwash operation condition, pipe lifetime was expected to be longer more than 100 years. The output of this research could be used as useful information of optimal design and operation factors in the membrane system.

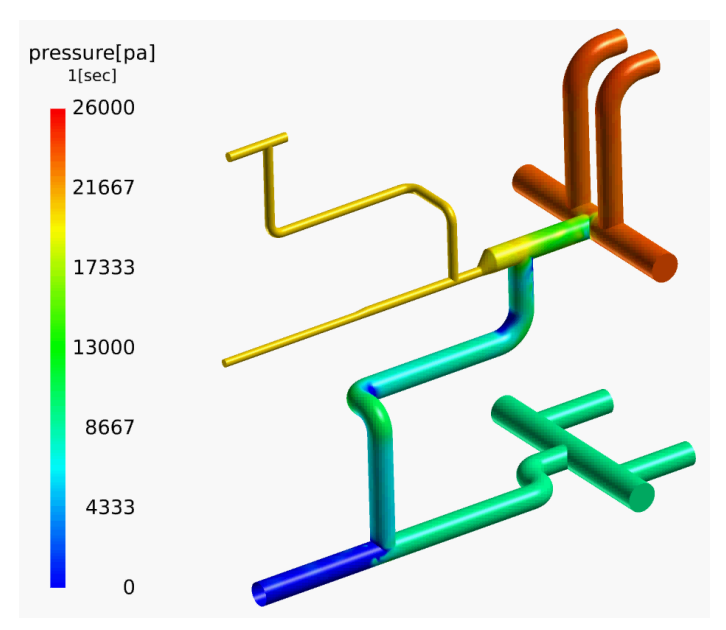

(a)

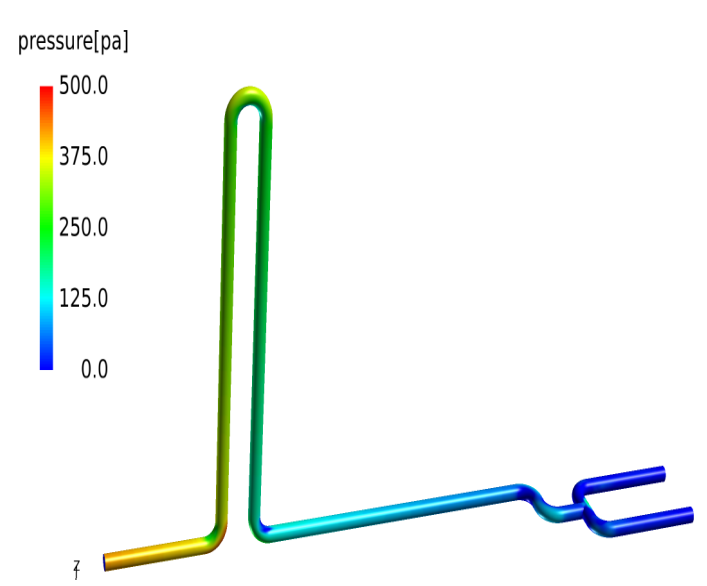

(b)

Figure 10. Fluid analysis of water and air passing the pipelines. (a) Water passing line; (b) Air passing line.

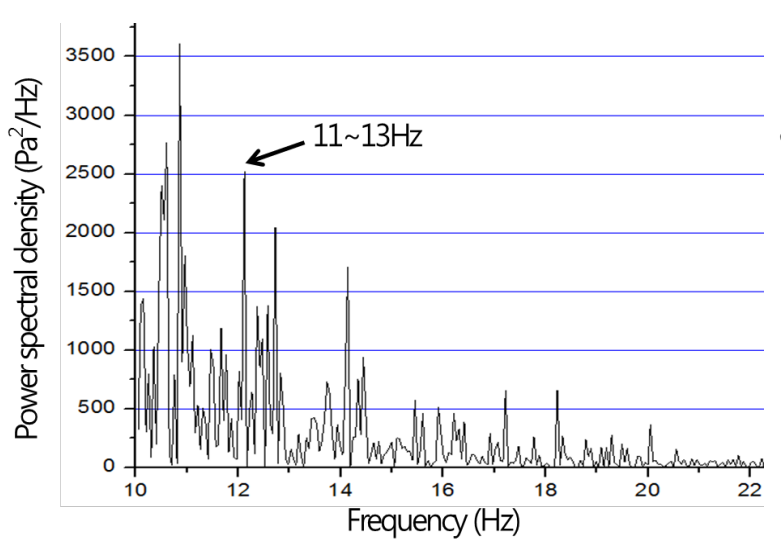

(a)

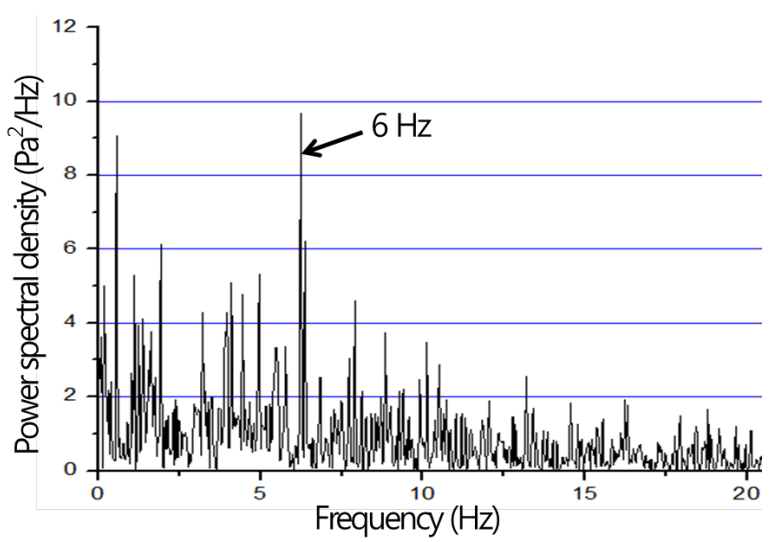

(b)

Figure 11. Frequency variation from FFT. (a) Concentrate pipe (water passing line); (b) Air pipe during the backwash mode.

\section{Conclusions}

In order to analyze the vibration source and pipeline integrity, flow analysis, frequency response analysis and fatigue analysis were performed. Also vibration measurement was performed in the real field. Field measurements showed that back wash mode had greater vibration compared to filtration mode, however, similar magnitude. Natural frequencies were identified 12, $22 \mathrm{~Hz}$, respectively for water and air under both operation modes. An 


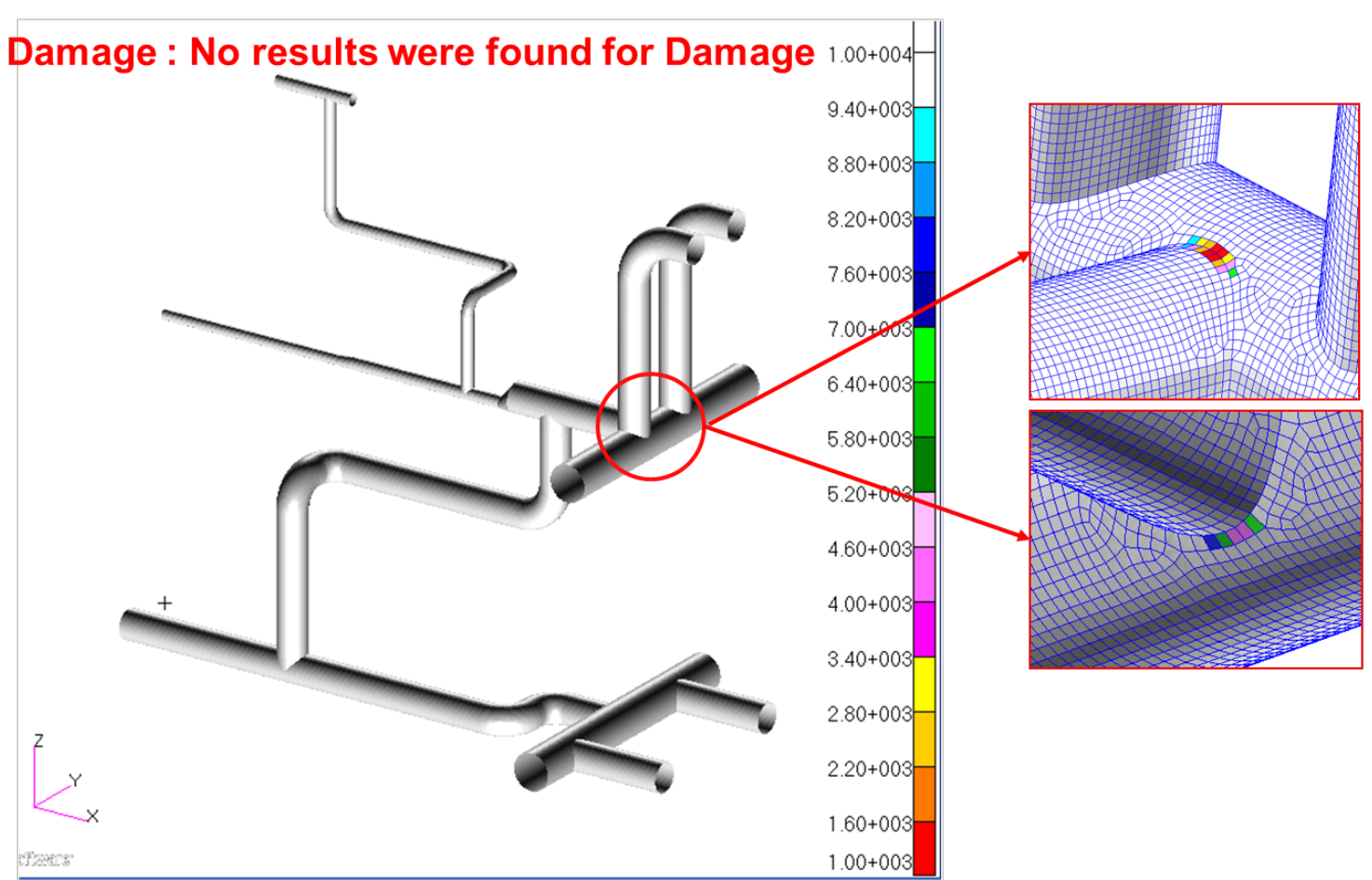

Figure 12. Fatigue analysis under the filtration mode (Min 2.31E372d (15 yr) Max: 9.52E17 d).

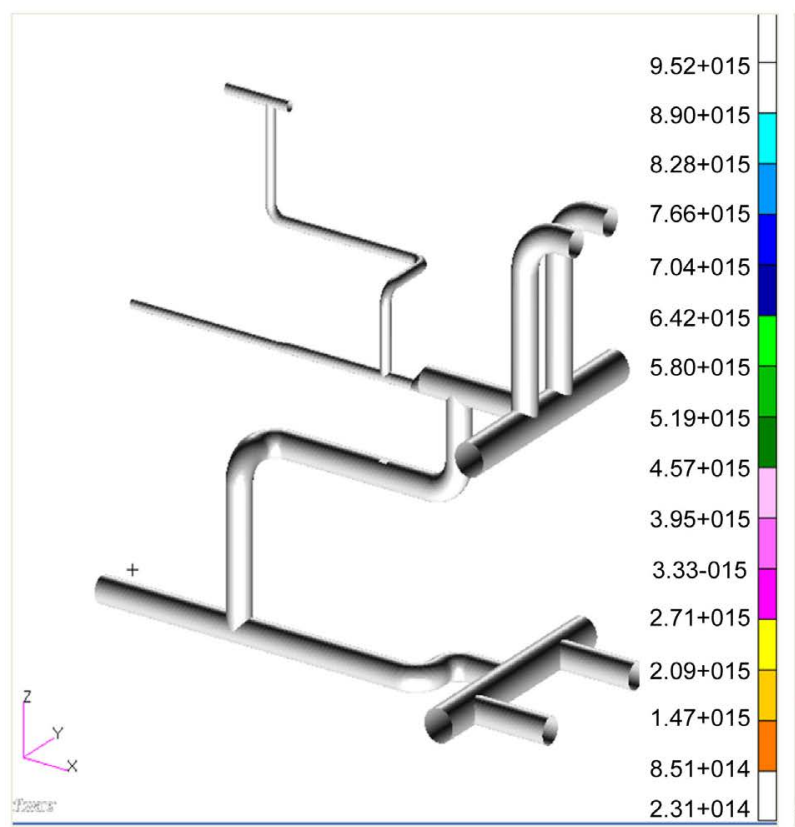

(a)

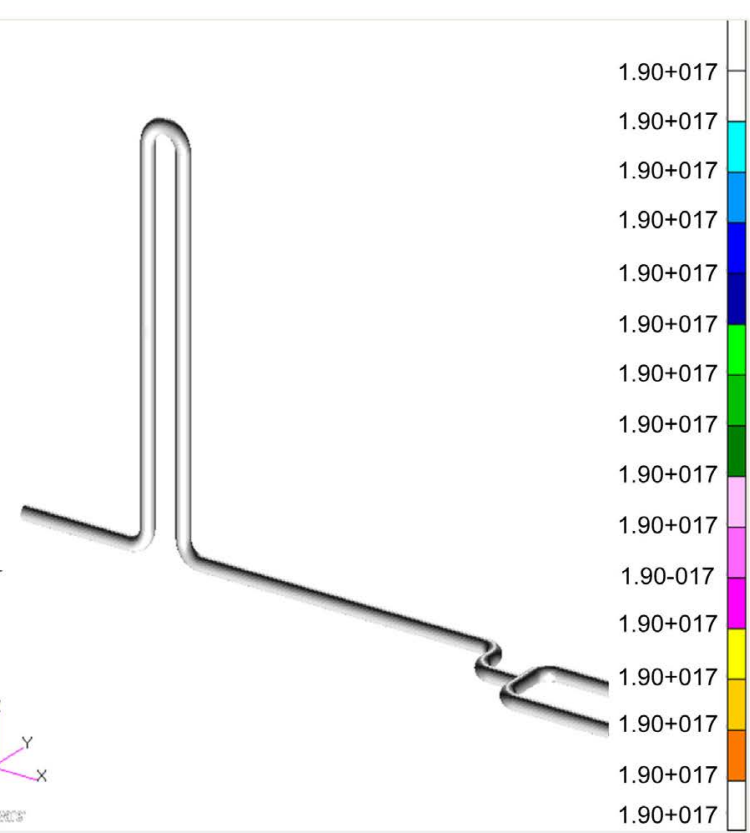

(b)

Figure 13. Fatigue analysis under the backwash mode. Min: 1120 (3 yr), Max: 1.0E4 (27 yr), Min: 1.9E17 d, Max: 9.52E17. (a) Lifetime analysis in water pipe; (b) Lifetime of air pipe at normal backwash.

analysis of frequency response and CFD resulted in a good agreement with the measured frequency. Fatigue analysis showed that the vibration appearing on the pipe was expected to have little effect. Fatigue lifetime was predicted more than 15 years under daily filtration and more than 27 years under daily backwash, resulting in minor damage on the pipe lifetime. 


\section{Acknowledgements}

This subject is supported by Korea Ministry of Environment as “The Eco-Innovation project (Global Top Project)”.

\section{References}

[1] Varbanets, M.P., Zurbrügg, C., Swartz, C. and Pronk, W. (2009) Decentralized Systems for Potable Water and the Potential of Membrane Technology, Water Research, 43, 245-265. http://dx.doi.org/10.1016/j.watres.2008.10.030

[2] Ahuja, S. (2013) Comprehensive Water Quality and Purification. Elsevier, Amsterdam, Boston.

[3] US EPA (2003) Membrane Filtration Guidance Manual Proposal.

[4] Gupta, V.K. (2013) Environmental Water. Elsevier, Amsterdam.

[5] Gijsbertsen-Abrahamse, A.J., Cornelissen, E.R. and Hofman, J.A.M.H. (2006) Fiber Failure Frequency and Causes of Hollow Fiber Integrity Loss. Desalination, 194, 251-258. http://dx.doi.org/10.1016/j.desal.2005.11.010

[6] GamalKhedr, M. (1998) A Case Study of RO Plant Failure Due to Membrane Fouling, Analysis and Diagnosis. Desalination, 120, 107-113. http://dx.doi.org/10.1016/S0011-9164(98)00207-0

[7] Lee, C.H. and Chang, K.H. (2013) Failure Pressure of a Pressurized Girth-Welded Super Duplex Stainlesssteel Pipe in Reverse Osmosis Desalination Plants. Energy, 61, 565-574. http://dx.doi.org/10.1016/j.energy.2013.08.056

[8] Chaudhuri, S. (2008) Philosophy of Integrity Assessment of Engineering Components. Materials Science and Engineering A, 489, 259-266. http://dx.doi.org/10.1016/j.msea.2007.12.013

[9] Jo, J.H., Lee, Y.S., Kim, Y.W. and Jin, H.L. (2012) Structural Integrity Evaluation of Large Main Steam Piping by Water Hammering. Journals of Mechanical Science and Technology, 36, 1103-1108.

[10] Guo, H., Wyart, Y., Perot, J., Nauleau, F. and Moulin, P. (2010) Low-Pressure Membrane Integrity Tests for Drinking Water Treatment: A Review. Water Research, 44, 41-57. http://dx.doi.org/10.1016/j.watres.2009.09.032

[11] Johnson, W.T. (1997) Automatic Monitoring of Membraneintegrity in Microfiltration Systems. Desalination, 113, 303-307. http://dx.doi.org/10.1016/S0011-9164(97)00146-X

[12] Johnson, W.T. (1998) Predicting Log Removal Performance of Membrane Systems Using In-Situ Integrity Testing. Filtration \& Separation, 1-35, 26-29.

[13] Adham, S.S., Jacangelo, J.G. and Laine, J.M. (1995) Low-Pressure Membranes: Assessing Integrity. Journal of American Water Works Association, 87, 62-75.

[14] Randles, N. (1997) Large Scale Operating Experience in Membrane Systems for Water Andwaste Water Reclamation. Desalination, 108, 205-211. http://dx.doi.org/10.1016/S0011-9164(97)00028-3

[15] Giglia, S. and Krishnan, M. (2008) High Sensitivity Binary Gas Integrity Test for Membrane Filters. Journal of Membrane Science, 323, 60-66. http://dx.doi.org/10.1016/j.memsci.2008.06.017

[16] Crozes, G.F., Sethi, S., Mi, B., Curl, J. and Marias, B. (2002) Improving Membrane Integrity Monitoring Indirect Methods to Reduce Plant Downtime and Increase Microbial Removal Credit. Desalienation, 149, 493-497. http://dx.doi.org/10.1016/S0011-9164(02)00787-7

[17] Laîne, J.M., Glucina, K., Chamant, M. and Simonie, P. (1998) Acoustic Sensor: A Novel Technique for Low Pressure Membrane. Desalination, 119, 73-77. http://dx.doi.org/10.1016/S0011-9164(98)00111-8

[18] Krantz, W.B., Lin, C.S., Sin, P.C.Y., Yeo, A. and Fane, A.G. (2011) An Integrity Sensor for Assessing the Performance of Low Pressure Membrane Modules in the Water Industry. Desalination, 283, 117-122. http://dx.doi.org/10.1016/j.desal.2011.05.029

[19] Choi, S.H., Yang, J., Suh, C. and Cho, J. (20111) Use of Fluorescent Silica Particles for Checking the Integrity of Microfiltration Membranes. Journal of Membrane Science, 367, 306-313. http://dx.doi.org/10.1016/j.memsci.2010.11.015

[20] Choi, J.B., Yeum, S.W., Ko, H.O., Kim, Y.J., Kim, H.K., Choi, Y.H. and Park, Y.W. (2010) Development of a WebBased Aging Monitoring System for an Integrity Evaluation of the Major Components in a Nuclear Power Plant, International Journal of Pressure Vessels and Piping, 87, 33-40.

[21] Norsok Standard (2009) Piping System Layout, Design and Structuralanalysis.

[22] Chang, Y.S., Jung, S.W., Lee, S.M., Choi, J.B. and Kim, Y.J. (2007) Fatigue Data Acquisition, Evaluation and Optimization of District Heating Pipes. Applied Thermal Engineering, 27, 2524-2535. http://dx.doi.org/10.1016/j.applthermaleng.2007.02.001

[23] Zhou, J. (2005) Reliability Assessment Method for Pressure Piping Containing Circumferential Defects Based on Fuzzy Probability. International Journal of Pressure Vessels and Piping, 82, 669-678. 
http://dx.doi.org/10.1016/j.ijpvp.2005.04.003

[24] Vinod, G., Sharma, P.K., Santosh, T.V., Prasad, M.H. and Vaze, K.K. (2014) New Approach for Risk Based Inspection of $\mathrm{H}_{2} \mathrm{~S}$ Based Process Plants. Annals of Nuclear Energy, 66, 13-19. http://dx.doi.org/10.1016/j.anucene.2013.08.042 